\title{
LETTERS
}

\section{Regulatory oversight for research tests and laboratory- developed diagnostics should be more nimble}

We read with interest the CMAJ commentary by Holloway and colleagues ${ }^{1}$ and agree enthusiastically with the authors' assertion that the Canadian regulatory system must be updated to address issues arising as molecular diagnostic technologies are developed and adopted. Although we recognize the need for regulatory guidelines and oversight, we also need to acknowledge the important balance of enabling access to novel tests that may provide new or refined diagnoses and treatments for patients with no other options.

We wish to highlight another class of tests that need to be considered, especially in precision health and the context of uncommon diseases (most often seen in children). These tests are performed in specialized research laboratories that, owing to the complexity of specific assays or the low number of cases, cannot be implemented feasibly or developed as a test in clinical laboratories at present. For example, RNA sequencing can detect fusions between 2 unrelated genes in a tumour. The detection of certain uncommon fusion proteins may support the use of molecularly tar- geted drugs in otherwise chemotherapyresistant deadly tumours. Not all genetic findings can be validated due to technique, especially when variants are uncommon or unique to an individual. Moreover, retesting and validation adds a considerable financial burden.

Under the current Ontario regulations ${ }^{2}$ this type of research testing would be unavailable to patients because the results must be validated in an accredited clinical laboratory before use for diagnosis or treatment.

At the Hospital for Sick Children, a multidisciplinary group of clinicians, scientists, legal experts and ethicists have formed the ENAbling Clinical Translation committee (ENACT), which is developing institutional guidelines and policies to address issues related to return of research results and regulatory gaps. We believe this type of local oversight is a critical first step and that new systems of federal or provincial regulatory oversight for research and laboratory-developed tests should be nimble and capable of rapid adjustment to the ever-changing landscape of advancing health care technologies, similar to the concept of a "regulatory sandbox" proposed for innovative health care products in the 2019 federal budget. ${ }^{3}$ Our collective goal is to foster rapid changes in health care and provide an agile, innovative and safe health care system in Canada that provides access to state-of-the-art diagnostics and therapies for all Canadian children and adults.

\section{Donna M. Berry PhD}

Program manager, research operations, Hospital for Sick Children, Toronto, Ont.

\section{Rulan S. Parekh MD MS}

Staff physician, associate chief of clinical research, Research Institute, Hospital for Sick Children, Toronto, Ont.

\section{Meredith S. Irwin MD}

Staff oncologist, associate chair of research, Department of Paediatrics, Hospital for Sick Children, Toronto, Ont.

Cite as: CMAJ 2019 December 16;191: E1388. doi: $10.1503 / \mathrm{cmaj} .73818$

\section{References}

1. Holloway K, Miller FA, Rousseau F, et al. Health Canada needs to act on laboratory-developed diagnostics. CMAJ 2019;191:E1067-9.

2. Laboratory and Specimen Collection Centre Licensing Act, R.S.O. 1990, c. L.1.

3. Mourneau WF. Ministry of Finance, Budget 2019: Investing in the Middle Class. Ottawa: House of Commons; 2019 March 19. Chapter 2, Part 5. Available: www.budget.gc.ca/2019/docs/plan/ chap-02-en.html\#Part-5-Building-a-Nation-of -Innovators (accessed Nov. 19).

Competing interests: None declared. 